\title{
Robust Linear Programming and Its Application to Water and Environmental Decision-Making under Uncertainty
}

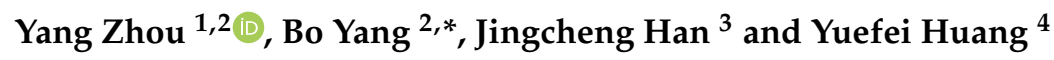 \\ 1 Water Science and Environmental Engineering Research Center, College of Chemical and Environmental \\ Engineering, Shenzhen University, Shenzhen 518060, China; yzhou@szu.edu.cn \\ 2 Department of Environmental Engineering, College of Chemical and Environmental Engineering, \\ Shenzhen University, Shenzhen 518060, China \\ 3 Water Research Center, Graduate School at Shenzhen, Tsinghua University, Shenzhen 518055, China; \\ han.jingcheng@sz.tsinghua.edu.cn \\ 4 State Key Laboratory of Hydroscience \& Engineering, Department of Hydraulic Engineering, Tsinghua \\ University, Beijing 100084, China; yuefeihuang@tsinghua.edu.cn \\ * Correspondence: boyang@szu.edu.cn or bo.yang.szu@outlook.com
}

Received: 4 November 2018; Accepted: 18 December 2018; Published: 21 December 2018

\begin{abstract}
In this study, we introduce a robust linear programming approach for water and environmental decision-making under uncertainty. This approach is of significant practical utility to decision makers for obtaining reliable and robust management decisions that are "immune" to the uncertainty attributable to data perturbations. The immunization guarantees that the chosen robust management plan will be implementable with no violation of the mandatory constraints of the problem being studied-i.e., natural resource supply constraint, environmental carrying capacity constraint, environmental pollution control constraint, etc.- and that the actual value of the objective will be no worse than the given estimation if the perturbations of data fall within the specified uncertainty set. A simplified example in regional water quality management is provided to help water and environmental practitioners to better understand how to implement robust linear programming from the perspective of application, as well as to illustrate the significance and necessity of implementing robust optimization techniques in real-world practices. Robust optimization is a growing research field that requires more interdisciplinary research efforts and engagements from water and environmental practitioners. Both may benefit from the advances of management science.
\end{abstract}

Keywords: robust optimization; water quality; water and environmental management; decision making; uncertainty; box uncertainty set

\section{Introduction}

Scarcity of freshwater has become a continuing worldwide problem as population increases, urbanization advances and climate changes. In many regions of the world, freshwater resources are insufficient to meet domestic, economic development and environmental needs. Meanwhile, the lack of adequate clean water has become a constraint on the advancement of economic development and the maintenance of a safe environment and healthy ecosystems [1-4]. To achieve long-term economic prosperity and environmental sustainability, policy-makers and water practitioners must engage with and actively collaborate with one another to explore a safe, sustainable way without compromising water availabilities that are essential to ecosystem functions and services [5]. Innovative water and land management approaches are needed for better planning and management of valuable freshwater resources and prevention of water-related risks and vulnerabilities. Multiple considerations 
in the social, economic and environmental aspects of water also need to be taken into account in decision-making processes in order to develop solutions that promote sustainable development over the long term [6-10].

It is already known that scientific management and contingency planning are the keys for addressing water-related conflicts and problems. A multitude of studies have been conducted to help decision makers to translate the sustainable development concept into operational management plans [11-14]. Mathematical programming, as one of the most useful tools that evaluate the competition scheme between sectors such as agriculture, industry and energy for limited natural resources, receives a continued interest from water, energy and environmental practitioners [15-19]. Mathematical programming has its particular advantages in providing a simplified and effective way for approaching the management problem of interest and in obtaining optimal solutions that reflect the tradeoffs between conflicting interests. A number of academic and industrial practices were conducted on the basis of an assumption that the problem data are known with certainty [20-24]. However, this is seldom the situation in practice. For example, the data may be derived from inferior estimation, affected by observational errors or affected by random events. In fact, uncertainty is a certain component of many natural systems. Failure to consider uncertainty in scientific and engineering practices may significantly reduce the reliability and robustness of model results, especially for the case that correction of decisions is not a readily available option for decision makers when the actual data reveals itself. As a result, there is a growing recognition that it is necessary to translate uncertain information into model parameters in order to obtain more safe and reliable solutions under uncertainty.

Previous research efforts have indeed improved our understanding of the applicable methods for dealing with various uncertainties in a water system [25-29]. Multiple types of uncertain information, including interval number, fuzzy set and probability distribution, can be translated into model parameters effectively through different mathematical techniques [30-35]. However, most of these efforts have limited practical values due to the limitation on providing reliable and robust managerial support under uncertainty. This is because these efforts were only focused on uncertainty characterization and propagation rather than the reliability analysis of decisions under uncertainty. For example, the inexact programming technique that has been extensively studied during the past two decades can provide a set of optimal interval solutions for supporting decision-making. However, this set is a collection of optimal solutions under a range of uncertain scenarios and the optimality of each solution from the set can only be guaranteed under specific scenarios rather than all scenarios. Accordingly, the optimal solutions from such a set are as vulnerable as the nominal optimal solutions that are derived without consideration of uncertainty if the risk assessment of constraint violations has not been carried out. Hence the research focus shall be aimed at how to obtain optimal, uncertainty-resistant solutions for supporting decision-making under uncertainty; otherwise, the solutions offered to decision makers are less meaningful in practice or much riskier than expected.

In this study, we introduce a robust linear programming approach that is capable of providing robust optimal solutions that are resistant to the uncertainty attributable to data perturbations. Infeasibility of the nominal optimal solutions can be effectively prevented and decision makers shall be confident of the reliability of their decisions when the actual data is within the given uncertainty set. Robust optimization is a young research field that has been mainly developed in the most recent 10 years. It has been applied in finance, operations research, electrical engineering, chemical engineering and computer science. Only a few exploratory studies have been carried out on the basis of the concept of robust optimization by water and environmental practitioners. It is thus necessary to promote this newly developed approach to water and environmental practitioners for obtaining reliable decision-making support under uncertainty. A semi-hypothetical example in water quality management is provided to illustrate the applicability of the robust linear programming approach and the vulnerability of the nominal optimal solutions in practice. The data of this example is mainly based on government reports and the numerical example has been simplified for the purpose of illustration. 
This example may help water and environmental practitioners to better understand the significance and necessity of implementing robust optimization techniques in real-world practices.

\section{Methodology}

Robust optimization is an applied research field that has received a revival of interest by a number of management scientists and operational researchers. The methodology of robust linear programming aims at finding solutions that are resistant to data uncertainty, especially for the case where the actual realization of uncertain parameters is within a given uncertainty set. Here a brief introduction of this methodology is given through a simple linear optimization problem with uncertain parameters. The general model of this type of linear optimization problems is as follows:

$$
\operatorname{Min}_{x} f(x)=c^{T} x
$$

subject to

$$
\begin{gathered}
A x \leq b \\
x \geq 0
\end{gathered}
$$

where $x$ is the decision variable and $c \in \mathrm{R}^{n}, A \in \mathrm{R}^{m \times n}$ and $b \in \mathrm{R}^{m}$ are the uncertain parameters.

In robust linear programming, the objective is to find the robust optimal value of $t$ within a set of robust feasible solutions that enable the inequality $c^{T} x \leq t$ to be active for all realizations of the objective function $f(x)$ from the uncertainty set $Z$. Hence, Model 1 can be converted into its robust counterpart as follows [36-39]:

$$
\operatorname{Min}_{x, t} t
$$

subject to

$$
\begin{gathered}
c^{T} x \leq t \\
A x \leq b \\
x \geq 0
\end{gathered}
$$

Here Constraints 5 and 6 with uncertain parameters $c$ and $b$ can be reformed as the following constraints:

$$
\begin{gathered}
c^{T} x-t \leq 0 \\
A x+b x_{n+1} \leq 0
\end{gathered}
$$

where $x_{n+1}=-1$. Accordingly, without loss of generality, the above constraints can be expressed as a universal constraint as follows:

$$
A(\varepsilon) x \leq b
$$

where $b \in R^{m}$ becomes a certain parameter and $\forall \varepsilon \in Z$. Since uncertainty is constraint-wise in robust optimization, decision makers may need to focus on the ith constraint of Constraint 10 in a robust linear programming problem:

$$
\sum_{i}^{n} a_{i j}(\varepsilon) x_{i} \leq b_{j}
$$

where $a_{i j}(\varepsilon)=\bar{a}_{i j}+\widetilde{a}_{i j} \varepsilon_{i j} ; \bar{a}_{i j}$ is the nominal value of $a_{i j}(\varepsilon)$; and $\widetilde{a}_{i j}$ is the positive length of perturbations. Constraint 11 then can be rewritten as follows:

$$
\sum_{i}^{n} \bar{a}_{i j} x_{i}+\sum_{i}^{n} \widetilde{a}_{i j} \varepsilon_{i j} x_{i} \leq b_{j}
$$


Robust linear programming requires the determination of a robust solution that is feasible for any realization of $\varepsilon$ in the given uncertainty set $Z$. Accordingly, the immunized constraint can be expressed as follows:

$$
\sum_{i}^{n} \bar{a}_{i j} x_{i}+\max _{\varepsilon \in Z}\left\{\sum_{i}^{n} \widetilde{a}_{i j} \varepsilon_{i j} x_{i}\right\} \leq b_{j}
$$

where $Z$ is the specified uncertainty set and the basic set is the box uncertainty set $Z=\left\{\varepsilon \mid\|\varepsilon\|_{\infty} \leq 1\right\}$.

\section{Case Study}

A semi-hypothetical regional water quality management problem is provided to demonstrate how to implement robust linear programming in practice. Consider a small watershed system that has a nature reserve in the area downstream of a river, as illustrated in Figure 1. Two dairy and beverage factories are the major polluters in the watershed system and are located at the upstream end of the river. A restrictive water quality regulation has been issued to protect the ecosystem services and functions of the nature reserve. It is estimated that the daily maximum allowable biochemical oxygen demand (BOD) mass load discharged from the dairy and beverage factories is $170 \mathrm{~kg}$, and that this BOD mass limit should be restrictively complied with and enforced so that the downstream water quality in the nature reserve can be maintained pursuant to the local water quality regulation. The dairy factory produces wastewater of $1200 \mathrm{~m}^{3}$ per day with the BOD concentration of $850 \mathrm{mg} / \mathrm{L}$ and the beverage factory produces wastewater of $4000 \mathrm{~m}^{3}$ per day with the BOD concentration of $400 \mathrm{mg} / \mathrm{L}$. The dairy and beverage factories have their own wastewater treatment systems and the BOD removal rates of the systems are $90 \%$ and $95 \%$, respectively. The treated wastewater from both the dairy and beverage factories satisfies the local effluent water quality standards and is permitted to be discharged into the river directly. The untreated wastewater is prohibited to be discharged directly into the river and may be discharged into the municipal sewage system with additional service fees. Different service fees apply for the untreated wastewater discharged into the municipal sewage system depending on the BOD concentration of the untreated wastewater. The watershed manager needs to decide how much wastewater is treated at the dairy and beverage factories by their own capacities and how much wastewater is discharged into the municipal sewage system without treatment. The objective of the watershed manager is to obtain a cost-effective management plan that satisfies the local water quality regulation. The watershed manager cannot tolerate violations of the regulatory water quality requirement. The summary of the problem parameters for the regional water quality management problem is provided in Table 1.

Table 1. Parameter values for the regional water quality management problem illustrated in Figure 1.

\begin{tabular}{cccccc}
\hline & $\begin{array}{c}\text { Influent BOD } \\
(\mathbf{m g} / \mathbf{L})\end{array}$ & $\begin{array}{c}\text { Wastewater } \\
\left(\mathbf{m}^{\mathbf{3}} / \mathbf{d}\right)\end{array}$ & $\begin{array}{c}\text { BOD Treatment } \\
\text { Cost } \mathbf{( \$ / t o n )}\end{array}$ & $\begin{array}{c}\text { BOD Removal } \\
\text { Efficiency }\end{array}$ & $\begin{array}{c}\text { Sewage Fee } \\
\left(\mathbf{\$} / \mathbf{m}^{\mathbf{3}}\right)\end{array}$ \\
\hline Dairy factory & 850 & 1200 & 400 & 0.9 & 0.56 \\
Beverage factory & 400 & 4000 & 500 & 0.95 & 0.25 \\
BOD mass limit $(\mathrm{kg})$ & 170 & & & & \\
Penalty $(\$ /$ ton) & 5000 & & & & \\
\hline
\end{tabular}




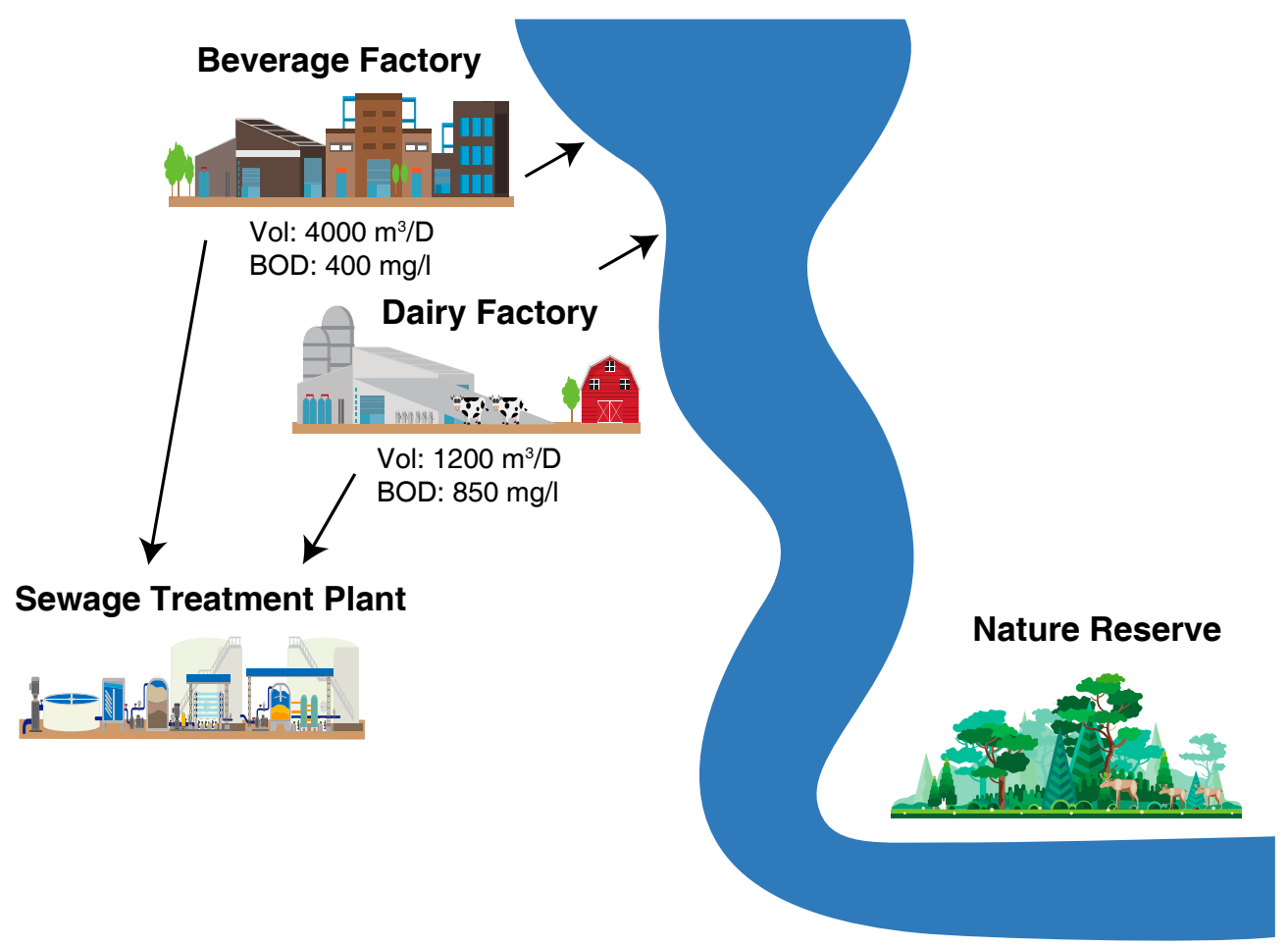

Figure 1. A schematic diagram of the regional water quality management problem.

This water quality management problem can be formulated as the following optimization model:

$$
\min \sum_{i=1}^{n} C_{i} B_{i} x_{i}+\sum_{i=1}^{n} S_{i} y_{i}
$$

Subject to:

(Water quality requirement)

$$
\sum_{i=1}^{n} B_{i}\left(1-E_{i}\right) x_{i} \leq L, \forall i
$$

(Wastewater treatment capacity)

$$
x_{i} \leq W_{i}, \forall i
$$

(Wastewater discharge capacity)

$$
y_{i}=W_{i}-x_{i}, \forall i
$$

where:

$C_{i}=$ the cost of BOD removal at factory $i$ (\$/ton)

$B_{i}=$ the BOD concentration of wastewater at factory $i\left(10^{-6}\right.$ ton $\left./ \mathrm{m}^{3}\right)$

$S_{i}=$ the service fee of wastewater discharged into the municipal sewage system from factory $i\left(\$ / \mathrm{m}^{3}\right)$

$E_{i}=$ the BOD removal efficiency of the wastewater treatment system at factory $i(\%)$

$L=$ the BOD mass limit $\left(10^{-3}\right.$ ton)

$W_{i}=$ the daily volume of wastewater produced at factory $i\left(\mathrm{~m}^{3} /\right.$ day)

$x_{i}=$ the volume of wastewater treated by the wastewater treatment system of factory $i\left(\mathrm{~m}^{3}\right)$

$y_{i}=$ the volume of wastewater discharged into the municipal sewage system from factory $i\left(\mathrm{~m}^{3}\right)$

As the perturbation of BOD removal efficiency at each factory is taken into account, the above optimization model can be converted to the following robust counterpart model: 


$$
\min \sum_{i=1}^{n} C_{i} B_{i} x_{i}+\sum_{i=1}^{n} S_{i} y_{i}
$$

Subject to:

(Water quality requirement)

$$
\sum_{i=1}^{n} B_{i} x_{i}-\sum_{i=1}^{n} B_{i} \bar{E}_{i} x_{i}-\min _{\varepsilon \in Z}\left\{\sum_{i=1}^{n} B_{i} \widetilde{E}_{i} x_{i} \varepsilon_{i}\right\} \leq L, \forall i
$$

(Wastewater treatment capacity)

$$
x_{i} \leq W_{i}, \forall i
$$

(Wastewater discharge capacity)

$$
y_{i}=W_{i}-x_{i}, \forall i
$$

where $\bar{E}_{i}$ is the nominal value of $E_{i} ; \widetilde{E}_{i}$ is the positive length of the perturbation of $E_{i} ; \varepsilon_{i} \in Z$ : $\left\{\varepsilon_{i} \mid\left\|\varepsilon_{i}\right\|_{\infty} \leq 1\right\}$ is the random variable subject to uncertainty; and $Z$ is the specified uncertainty set. Here we consider a box uncertainty set and a case that the BOD removal rates drift in the $5 \%$ and $2 \%$ margins of the nominal values at the dairy and beverage factories, respectively.

\section{Result Analysis}

In this example we studied the nominal model at first so that the nominal optimal solution of Model 9 can be used to provide a detailed contrast to the robust optimal solution of the robust counterpart model, i.e., Model 10. The solution of Model 9 can be obtained easily and it suggests such a management plan: treat $1200 \mathrm{~m}^{3}$ of wastewater (no discharge into the municipal sewage system) at the dairy factory and treat $3400 \mathrm{~m}^{3}$ of wastewater $\left(600 \mathrm{~m}^{3}\right.$ of wastewater discharged into the municipal sewage system) at the beverage factory for a total cost of $\$ 1238$ per day. It is known that not all problem data could be viewed as perfectly reliable in practice. For example, one can hardly believe that the BOD removal rates of the wastewater treatment systems are exactly the nominal data, i.e., $90 \%$ at the dairy factory and $95 \%$ at the beverage factory. In reality, these rates vary around the nominal values. If the perturbations of the BOD removal rates are taken into account, the nominal optimal solution may make the model infeasible. In fact, this nominal optimal solution is sensitive to the model parameters provided in this case study. In particular, since the water quality requirement constraint (i.e., Constraint 15) is active with this optimal solution (i.e., there is no additional BOD amount allowable to be discharged into the river), a slight perturbation of the parameters that describe this constraint could make this nominal optimal solution infeasible. In other words, the regulatory water quality requirement could be violated when a small change occurs in the BOD removal rates.

Robust linear programming provides a feasible way to prevent such violations of the decision criteria and suggests a more rational and robust optimal solution for the management problem under uncertainty. As the perturbations of the BOD removal rates by $5 \%$ and $2 \%$ at the dairy and beverage factories are taken into account, the robust optimal solution of Model 10 suggests the following management plan: treat $483.57 \mathrm{~m}^{3}$ of wastewater $\left(716.43 \mathrm{~m}^{3}\right.$ of wastewater discharged into the municipal sewage system) at the dairy factory and treat $4000 \mathrm{~m}^{3}$ of wastewater (no discharge into the municipal sewage system) at the beverage factory for a total cost of $\$ 1366$ per day. Since the nominal solution of Model 9 leads to the violation of the water quality requirement constraint, it is necessary to assume a monetary system penalty with respect to the violation so that the negative effect of the violation caused by the non-robust nominal solution could be evaluated. Hence, the system penalty is assumed to be $\$ 5000$ per ton for the unauthorized discharge of BOD mass load into the river. Now the negative effect of the violation can be estimated and shows that the nominal optimal solution would result in a much higher total cost, increasing from $\$ 1238$ to $\$ 1597$ in the worst scenario. The actual total cost will increase by, at most, $29 \%$ compared to the expected value. Compared with the nominal optimal solution, the robust optimal solution suggests a higher total cost to prevent the violation of 
the regulatory water quality requirement. The estimated robust total cost increases the nominal total cost by $10 \%$ (i.e., increasing from $\$ 1238$ to $\$ 1366$ ) but it guarantees that no extra cost will be added to this estimation if the perturbations of parameters are within the given uncertainty set. This provides two decision-making alternatives: a certain $10 \%$ increase in the total cost with no penalty or a lower expected total cost with a potential increase by as much as $29 \%$. It is apparent that the robust solution is favorable in practice since most decision makers prefer uncertainty-aversion decisions. Moreover, from a viewpoint of the tradeoff between the cost and the risk, it is still favorable in adding $10 \%$ initial cost for insurance to avoid a potential $29 \%$ cost overrun.

The comparison between the solutions of Models 9 and 10 is given in Figure 2. It shows two conflicting management plans for this regional water quality management problem. The nominal solution suggests that the dairy factory needs to treat all its wastewater by its own wastewater treatment system and no wastewater is required to be discharged through the municipal sewage system. Indeed, it is a somewhat easy decision to be made since it is consistent with our common sense for a minimization problem. The dairy factory has a lower BOD removal cost and a higher sewage service fee attributable to the higher BOD concentration within its wastewater. It seems to be reasonable by giving the dairy factory a top priority for the purpose of minimizing the total cost. However, this is true in the theoretical condition where no uncertainty is involved. As the perturbations of the BOD removal rates are taken into account, a different priority rule for the dairy and beverage factories may be given. In fact, the robust counterpart model gives a conflicting management plan. The robust solution suggests that the beverage factory needs to treat all its wastewater by its own wastewater treatment system rather than giving the dairy factory such a priority. The dairy factory needs to treat only a portion of its wastewater (i.e., $483.57 \mathrm{~m}^{3}$ ) and the remaining wastewater (i.e., $716.43 \mathrm{~m}^{3}$ ) needs to be discharged into the municipal sewage system directly with a certain amount of sewage service fee. Although the beverage factory has a higher BOD removal cost per unit, the robust solution indicates that giving the beverage factory a top priority over the dairy factory to treat all its wastewater is a robust and cost-effective decision under uncertainty. This robust solution can be considered "immune" to respective $5 \%$ and $2 \%$ fluctuations of the BOD removal efficiency at the dairy and beverage factories. The immunization guarantees that the robust water quality management plan will be implementable without violation of the regulatory water quality requirement and that the total cost will be no more than the expected estimation no matter what the BOD removal efficiency ends up being, as long as it falls within the defined uncertainty set.

We also studied four boundary scenarios of uncertain parameter combinations for nominal and robust solutions. As can be seen from Figure 3, the actual cost of the nominal solution could increase by $\$ 359$ in the worst scenario (i.e., the scenario of " - “" where - denotes the lower bound of uncertain parameters) and the BOD over-discharging load due to negligent environmental violation is $72 \mathrm{~kg}$ in total. Compared with the worst scenario, the actual cost of the nominal solution in one of the non-pessimistic scenarios (i.e., the scenario of "- +") could increase by about one-third of the portion of cost overrun in the worst scenario and the BOD over-discharging load is about $20 \mathrm{~kg}$. It indicates that the nominal solution could also result in negligent environmental violation in a non-pessimistic scenario. In the other two scenarios, the nominal solution may lead to no environmental violations but this solution is not optimal for the two scenarios. The actual cost could be further reduced by about $2.5 \%$ if modification of the nominal decisions is allowable after the uncertain parameters reveal their actual values. Figure 4 shows the risk and optimality analysis of the robust solution under the four boundary scenarios. It shows that the robust solution guarantees no environmental violations in all four scenarios but is less optimal in the last three scenarios. The actual cost could be further reduced by at least $8 \%$ in these scenarios if modification of the decisions is allowable after the uncertain parameters reveal their actual values.

The comparison between the nominal and robust optimal solutions with respect to the feasibility of the water quality requirement constraint within the defined uncertainty set is provided in Figure 5 . As can be seen from Figure $5 \mathrm{a}$, the nominal solution makes the water quality requirement constraint 
feasible with a probability of 0.50 within the given box uncertainty set. As a result, the watershed manager has to undertake a 50\% chance of violating the regulatory water quality requirement without informed knowledge of such a risk. In contrast to the nominal solution, the robust solution, shown in Figure $5 b$, makes the water quality requirement constraint feasible within the entire uncertainty set. Hence robust linear programming techniques may give the watershed manager more confidence to implement a reliable and robust water quality management plan under uncertainty.

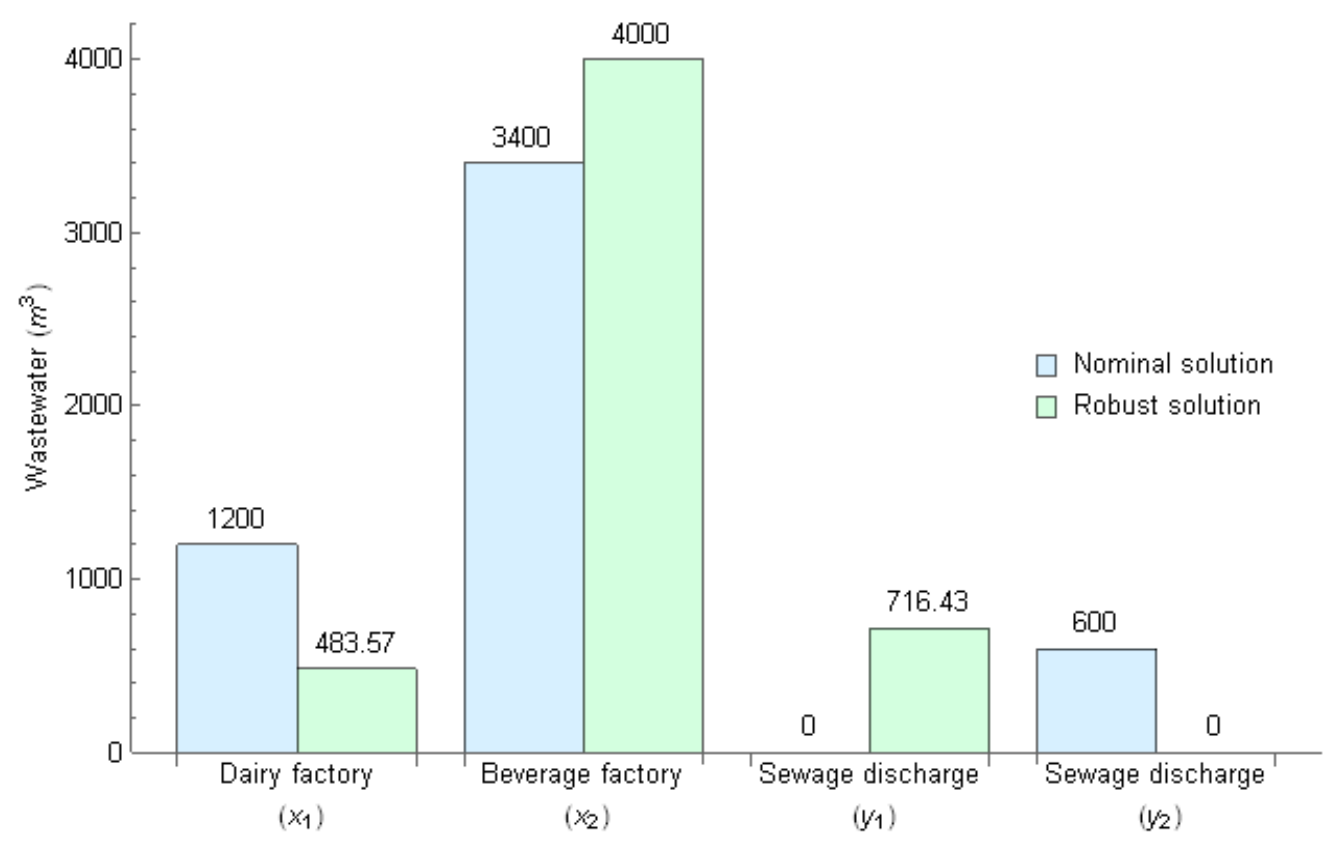

Figure 2. The comparison of nominal optimal and robust optimal solutions.

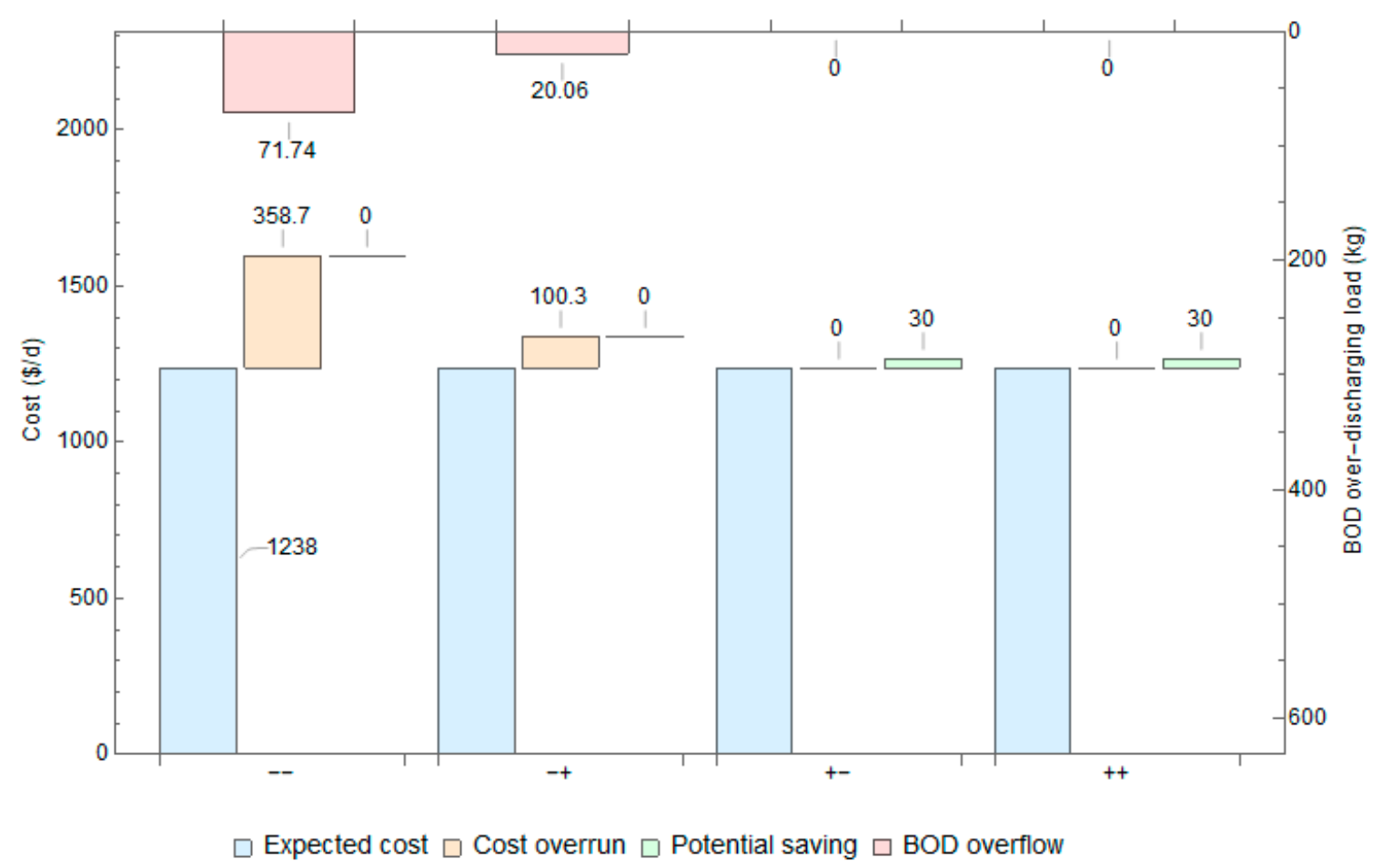

Figure 3. Risk and optimality analysis of the nominal solution under four boundary scenarios of uncertain parameters combinations (where - and + denote the lower and upper bounds). 


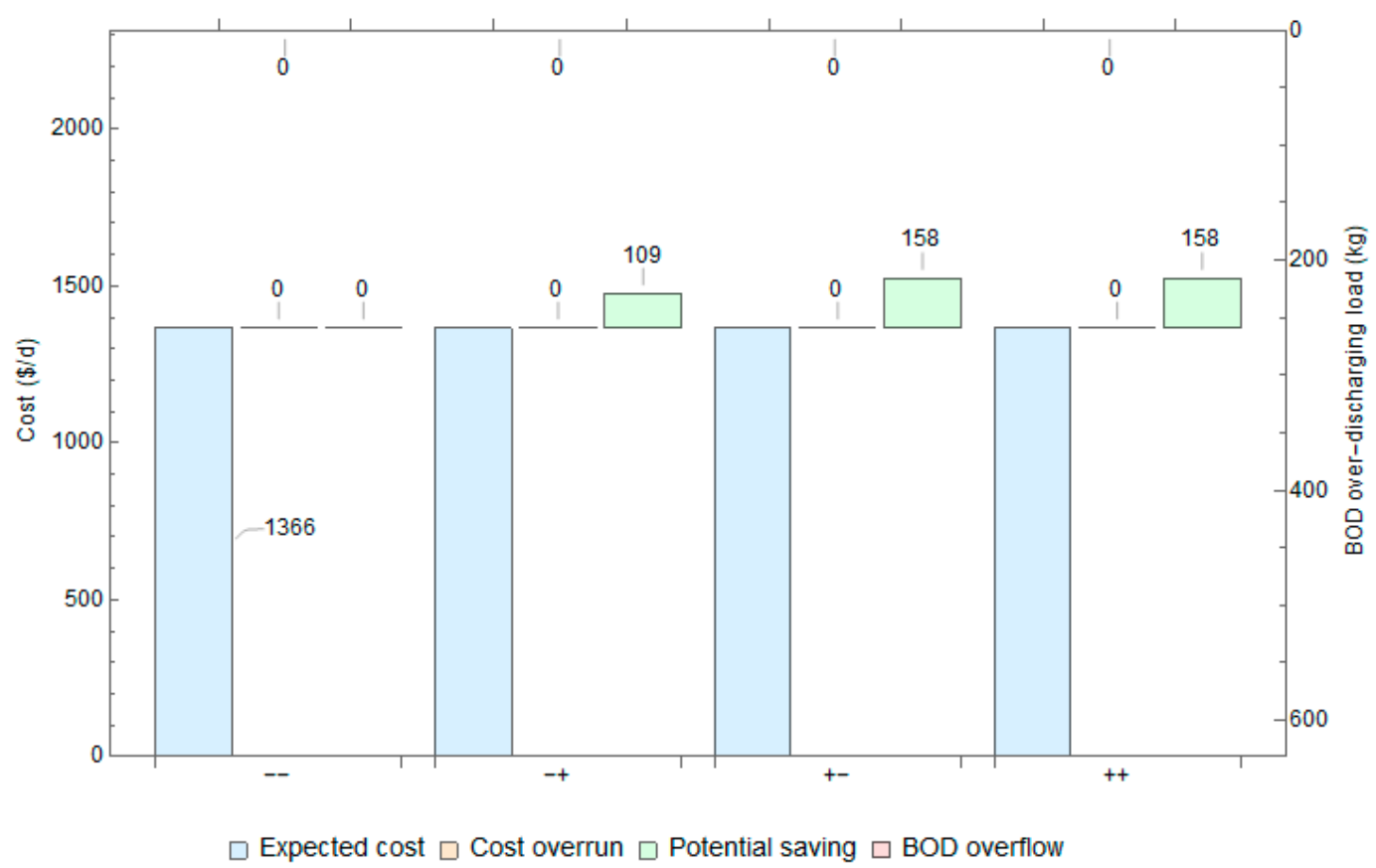

Figure 4. Risk and optimality analysis of the robust solution under four boundary scenarios of uncertain parameters combinations (where - and + denote the lower and upper bounds).
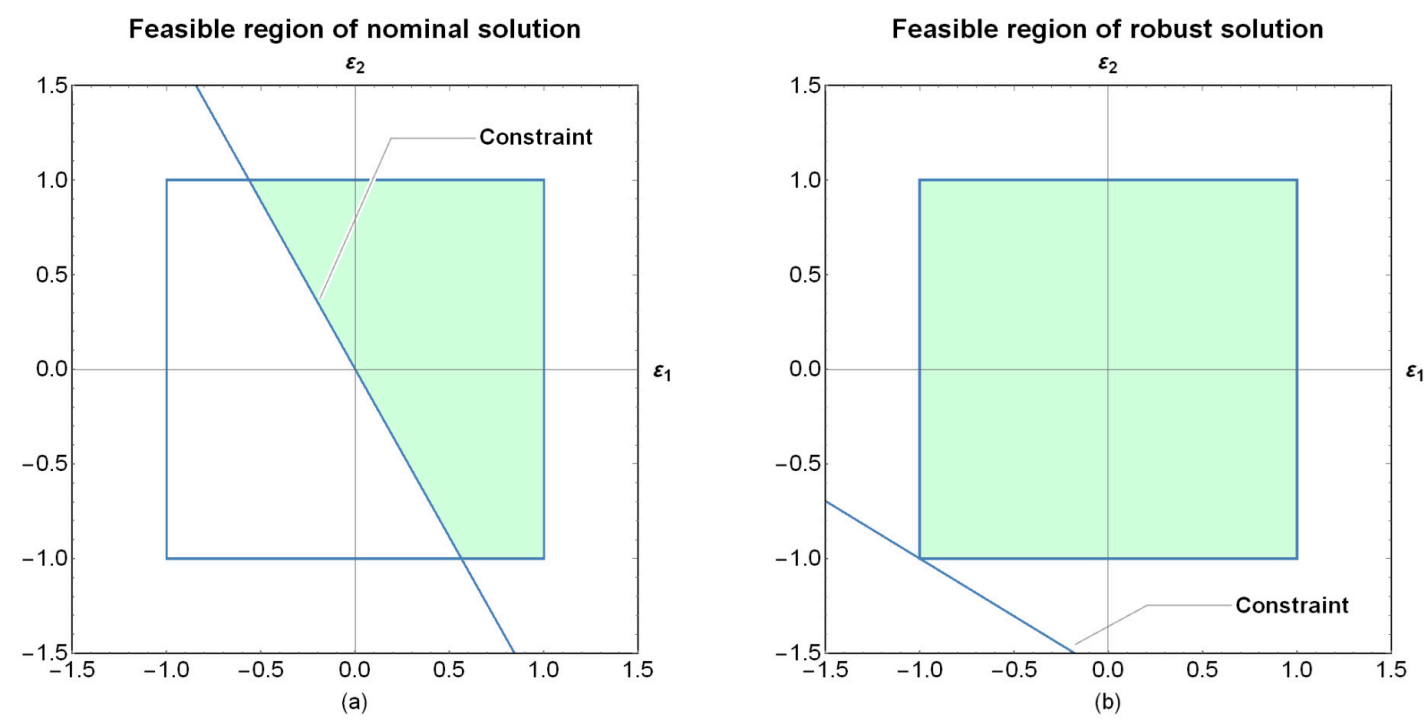

Figure 5. The comparison of the feasible region between nominal optimal solution and robust optimal solution with respect to the water quality requirement constraint within the specified uncertainty set.

\section{Discussion}

This regional water quality management example was developed for the purpose of illustrating the application of robust linear programming and the main limitation of previous methods in dealing with water and environmental management problems under uncertainty. A number of simplifications with respect to real-world water quality management problems had been made to help water and environmental practitioners to better understand the significance and necessity of implementing robust optimization techniques in real-world managerial practices. Although this representative example was simplified for the purpose of illustration, its generality and flexibility allow this example to be further improved and extended to real-world applications with some modifications based on decision makers' actual needs. For example, more water quality parameters such as chemical oxygen demand 
(COD), total suspended solids (TSS), NH4-N, NO3-N, and total phosphorus may need to be included. Detailed cost estimation may need to be performed. The process of environmental pollutant transport in the study area may need to be simulated prior to the development of a regional management model. These improvements will significantly enhance the suitability and practicality of this example in dealing with real-world problems.

Robust optimization is an optimization technique that focuses on the worst scenarios under uncertainty. It guarantees the certainty of the objective value and the feasibility of robust decisions in all scenarios. As a result, the optimality of robust decisions in other scenarios has to be compromised. In this study, we studied the basic uncertainty set in robust optimization-the box uncertainty set. This uncertainty set ensures that no violation of constraints will occur if the perturbations of uncertain parameters fall within the box uncertainty set. However, the robust solution obtained from this set is particularly conservative so that its practicality may also be discounted unless decision makers have no tolerance for the violation of constraints. If the decision makers are willing to accept a small degree of violation of the predetermined constraints, either the ellipsoidal uncertainty set or the polyhedral uncertainty set may be employed for obtaining a relatively conservative solution with competitive robustness under uncertainty.

\section{Conclusions}

In this study, we introduced a robust linear programming approach for water and environmental decision-making under uncertainty. This approach is of significant practical utility to decision makers for obtaining reliable and robust management decisions that are "immune" to the uncertainty attributable to data perturbations. The immunization guarantees that the chosen robust management plan will be implementable with no violation of the mandatory constraints of the problem being studied-i.e., natural resource supply constraint, environmental carrying capacity constraint, environmental pollution control constraint, etc.-and that the actual value of the objective will be no worse than the given estimation if the perturbations of data fall within the specified uncertainty set. Prevention or reduction of the violation of the mandatory constraints is particularly important to a successful water or environmental management plan, especially when it is known that the nominal solution may have a 50\% chance of violating the mandatory constraints under uncertainty.

Nowadays the common management strategy that has been widely applied in water and environmental management, i.e., hedging the risk of environmental violations by economic compensation, is not recommended in practice. The natural world can no longer function as it was and has become less tolerant of negligent environmental violations than us-the debtors. So-called "economic compensation" is collected by people rather than the natural world itself as the creditor. Furthermore, environmental and ecological restoration requires a long-term effort and is far more difficult and costly than our expectation. It thus requires decision makers to be more thoughtful about developing an implementable management plan with resistance to uncertainty. A conservative attitude from decision makers with respect to environmental violations may provide more flexibility in developing a sustainable future for our society.

A simplified numerical example in water quality management was provided to help water and environmental practitioners to better understand how to implement robust linear programming from the perspective of application. This representative example is extendable and can be further improved based on actual needs in real-world practices. Overall, robust optimization is a growing research field that requires more interdisciplinary research efforts and engagements from water and environmental practitioners. Its main practical value lies in potentially providing water and environmental decision makers with a more rational and reliable way to address management and planning problems under uncertainty. In fact, the risk of negligent environmental violations attributable to non-robust decisions shall not be underestimated under uncertain conditions. The risk level associated with the optimal solution needs to be realized by decision makers and be appropriately considered in the decision-making process. Expected optimality shall no longer be the dominant 
decision criterion and a sustainable management plan shall always be a result of the tradeoff between the optimality and robustness of the management decisions. It is expected that both water and environmental decision makers may benefit from the advances of management science. In future research, complicated real-world cases will be studied, and the ellipsoidal and polyhedral uncertainty sets will be employed to evaluate the practicality of robust optimization.

Author Contributions: Conceptualization, Y.Z. and Y.H.; Data curation, Y.Z., B.Y. and J.H.; Formal analysis, Y.Z. and J.H.; Funding acquisition, B.Y.; Investigation, Y.Z. and J.H.; Methodology, Y.Z.; Project administration, B.Y.; Resources, B.Y. and Y.H.; Software, Y.Z.; Validation, Y.Z.; Visualization, Y.Z.; Writing-original draft, Y.Z.; Writing-review \& editing, Y.Z. and B.Y.

Funding: This research was funded by the National Natural Science Foundation of China (21777106), and by the National Major Science \& Technology Program for Water Pollution Control \& Treatment (2017ZX07202).

Acknowledgments: We are grateful to the editor and three anonymous reviewers for their insightful comments and suggestions.

Conflicts of Interest: The authors declare no conflict of interest.

\section{References}

1. Cosgrove, W.J.; Loucks, D.P. Water management: Current and future challenges and research directions. Water Resour. Res. 2015, 51, 4823-4839. [CrossRef]

2. Daher, B.; Mohtar, R.; Pistikopoulos, E.; Portney, K.; Kaiser, R.; Saad, W. Developing socio-techno-economicpolitical (step) solutions for addressing resource nexus hotspots. Sustainability 2018, 10, 512. [CrossRef]

3. Zhai, Y.Y.; Huang, G.H.; Wang, X.Q.; Zhou, X.; Lu, C.; Li, Z. Future projections of temperature changes in ottawa, canada through stepwise clustered downscaling of multiple gcms under rcps. Clim. Dyn. 2018. [CrossRef]

4. Zheng, M.S.; Ma, L.K.; Li, T.H.; Huang, R. Rapid assessment method for eco-water deficit in catchments. J. Environ. Inform. 2017, 30, 149-160. [CrossRef]

5. Bigas, H. The Global Water Crisis: Addressing an Urgent Security Issue; UNU-INWEH: Hamilton, ON, Canada, 2012; Volume 2011-2012.

6. Xin, X.Y.; Huang, G.H.; An, C.J.; Huang, C.; Weger, H.; Zhao, S.; Zhou, Y.; Rosendahl, S. Insights into the toxicity of triclosan to green Microalga chlorococcum sp. Using synchrotron-based fourier transform infrared spectromicroscopy: Biophysiological analyses and roles of environmental factors. Environ. Sci. Technol. 2018, 52, 2295-2306. [CrossRef] [PubMed]

7. An, C.J.; McBean, E.; Huang, G.H.; Yao, Y.; Zhang, P.; Chen, X.J.; Li, Y.P. Multi-soil-layering systems for wastewater treatment in small and remote communities. J. Environ. Inform. 2017, 27, 131-144. [CrossRef]

8. Liu, L.R.; Huang, G.H.; Baetz, B.W.; Zhang, K.Q. Environmentally-extended input-output simulation for analyzing production-based and consumption-based industrial greenhouse gas mitigation policies. Appl. Energy 2018, 232, 69-78. [CrossRef]

9. Zhou, Y.; Huang, G.; Baetz, B.W. Multilevel factorial fractional programming for sustainable water resources management. J. Water Resour. Plan. Manag. ASCE 2016, 142, 04016063. [CrossRef]

10. Zhou, Y.; Huang, G.H.; Zhu, H.; Li, Z.; Chen, J.P. A factorial dual-objective rural environmental management model. J. Clean. Prod. 2016, 124, 204-216. [CrossRef]

11. Xiao, Y.; Fang, L.P.; Hipel, K.W. Centralized and decentralized approaches to water demand management. Sustainability 2018, 10, 3466. [CrossRef]

12. Thomsen, M.; Romeo, D.; Caro, D.; Seghetta, M.; Cong, R.G. Environmental-economic analysis of integrated organic waste and wastewater management systems: A case study from Aarhus city (Denmark). Sustainability 2018, 10, 3742. [CrossRef]

13. Paul, S.S.; Li, J.; Wheate, R.; Li, Y. Application of object oriented image classification and markov chain modeling for land use and land cover change analysis. J. Environ. Inform. 2018, 31, 30-40. [CrossRef]

14. Liu, L.R.; Huang, G.H.; Baetz, B.W.; Huang, C.Z.; Zhang, K.Q. A factorial ecologically-extended input-output model for analyzing urban ghg emissions metabolism system. J. Clean. Prod. 2018, 200, 922-933. [CrossRef]

15. Chen, X.J.; Huang, G.H.; Zhao, S.; Cheng, G.H.; Wu, Y.H.; Zhu, H. Municipal solid waste management planning for Xiamen city, China: A stochastic fractional inventory-theory-based approach. Environ. Sci. Pollut. Res. 2017, 24, 24243-24260. [CrossRef] [PubMed] 
16. Song, T.N.; Huang, G.H.; Zhou, X.; Wang, X.Q. An inexact two-stage fractional energy systems planning model. Energy 2018, 160, 275-289. [CrossRef]

17. Zhai, Y.Y.; Huang, G.H.; Zhou, Y.; Zhou, X. A factorial dual-interval programming approach for planning municipal waste management systems. J. Environ. Eng. ASCE 2016, 142, 04016033. [CrossRef]

18. Chen, X.J.; Huang, G.H.; Zhu, H.; Suo, M.Q.; Dong, C. Inexact inventory theory-based waste management planning model for the city of Xiamen, China. J. Environ. Eng. ASCE 2016, 142, 04016013. [CrossRef]

19. Zhou, Y.; Li, Y.P.; Huang, G.H.; Zhou, Y. A robust approach for planning electric power systems associated with environmental policy analysis. Electr. Power Syst. Res. 2013, 95, 99-111. [CrossRef]

20. Diffendorfer, J.E.; Richards, P.M.; Dalrymple, G.H.; DeAngelis, D.L. Applying linear programming to estimate fluxes in ecosystems or food webs: An example from the herpetological assemblage of the freshwater everglades. Ecol. Model. 2001, 144, 99-120. [CrossRef]

21. Peña-Haro, S.; Pulido-Velazquez, M.; Sahuquillo, A. A hydro-economic modelling framework for optimal management of groundwater nitrate pollution from agriculture. J. Hydrol. 2009, 373, 193-203. [CrossRef]

22. Raymer, A.K.; Gobakken, T.; Solberg, B.; Hoen, H.F.; Bergseng, E. A forest optimisation model including carbon flows: Application to a forest in norway. For. Ecol. Manag. 2009, 258, 579-589. [CrossRef]

23. Roberts, K.P.; Turner, D.A.; Coello, J.; Stringfellow, A.M.; Bello, I.A.; Powrie, W.; Watson, G.V.R. Swims: A dynamic life cycle-based optimisation and decision support tool for solid waste management. J. Clean. Prod. 2018, 196, 547-563. [CrossRef]

24. Sarimveis, H.K.; Angelou, A.S.; Retsina, T.R.; Rutherford, S.R.; Bafas, G.V. Optimal energy management in pulp and paper mills. Energy Convers. Manag. 2003, 44, 1707-1718. [CrossRef]

25. Chen, C.; Huang, G.H.; Li, Y.P.; Zhou, Y. A robust risk analysis method for water resources allocation under uncertainty. Stoch. Environ. Res. Risk Assess. 2013, 27, 713-723. [CrossRef]

26. Huang, G.H.; Loucks, D.P. An inexact two-stage stochastic programming model for water resources management under uncertainty. Civ. Eng. Environ. Syst. 2000, 17, 95-118. [CrossRef]

27. Zhou, Y.; Huang, G.H.; Yang, B.T. Water resources management under multi-parameter interactions: A factorial multi-stage stochastic programming approach. Omega 2013, 41, 559-573. [CrossRef]

28. Hollinshead, S.P.; Lund, J.R. Optimization of environmental water purchases with uncertainty. Water Resour. Res. 2006, 42. [CrossRef]

29. Herman, J.D.; Zeff, H.B.; Reed, P.M.; Characklis, G.W. Beyond optimality: Multistakeholder robustness tradeoffs for regional water portfolio planning under deep uncertainty. Water Resour. Res. 2014, 50, 7692-7713. [CrossRef]

30. Xin, X.Y.; Huang, G.H.; Sun, W.; Zhou, Y.; Fan, Y.R. Factorial two-stage irrigation system optimization model. J. Irrig. Drain. Eng. 2016, 142, 04015056. [CrossRef]

31. Chen, J.P.; Huang, G.H.; Baetz, B.W.; Lin, Q.G.; Dong, C.; Cai, Y.P. Integrated inexact energy systems planning under climate change: A case study of Yukon Territory, Canada. Appl. Energy 2018, 229, 493-504. [CrossRef]

32. Hu, J.; Sun, L.; Li, C.H.; Wang, X.; Jia, X.L.; Cai, Y.P. Water quality risk assessment for the laoguanhe river of china using a stochastic simulation method. J. Environ. Inform. 2018, 31, 123-136. [CrossRef]

33. Zhou, Y.; Huang, G.H.; Wang, S.; Li, Z.; Zhou, Y. Factorial fuzzy programming for planning water resources management systems. J. Environ. Plan. Manag. 2016, 59, 1855-1872. [CrossRef]

34. Zhou, Y.; Huang, G.; Wang, S.; Zhai, Y.Y.; Xin, X.Y. Water resources management under dual uncertainties: A factorial fuzzy two-stage stochastic programming approach. Stoch. Environ. Res. Risk Assess. 2016, 30, 795-811. [CrossRef]

35. Huang, C.Z.; Nie, S.; Guo, L.; Fan, Y.R. Inexact fuzzy stochastic chance constraint programming for emergency evacuation in qinshan nuclear power plant under uncertainty. J. Environ. Inform. 2017, 30, 63-78. [CrossRef]

36. Ben-Tal, A.; El Ghaoui, L.; Nemirovski, A.S. Robust Optimization; Princeton University Press: Princeton, NJ, USA, 2009; p. 576.

37. Ben-Tal, A.; Nemirovski, A. Robust solutions of uncertain linear programs. Oper. Res. Lett. 1999, 25, 1-13. [CrossRef]

38. Bertsimas, D.; Brown, D.; Caramanis, C. Theory and applications of robust optimization. SIAM Rev. 2011, 53, 464-501. [CrossRef]

39. Bertsimas, D.; Sim, M. The price of robustness. Oper. Res. 2004, 52, 35-53. [CrossRef]

(C) 2018 by the authors. Licensee MDPI, Basel, Switzerland. This article is an open access article distributed under the terms and conditions of the Creative Commons Attribution (CC BY) license (http:/ / creativecommons.org/licenses/by/4.0/). 